\title{
Factors Influencing Activity of Xiwang Road Ground Fissure Based on Time-series Interferometric Synthetic Aperture Radar and Detection of Land Cover Changes Using Optical Imaging
}

\author{
$\mathrm{Xi} \mathrm{Liu},{ }^{1}$ Jing $\mathrm{Ma},{ }^{2}$ and Shan $\mathrm{Su}^{1 *}$ \\ ${ }^{1}$ Heilongjiang Surveying and Mapping Instrument Calibration Station, Haerbin 150000, China \\ ${ }^{2}$ Beijing Institute of Geological and Prospecting Engineering, Beijing 100048, China
}

(Received October 28, 2020; accepted December 10, 2020)

Keywords: ground fissure, time-series InSAR, SBAS-InSAR, change detection, influencing factors

In this study, small baseline subsets interferometric synthetic aperture radar (SBAS-InSAR) was used to monitor the surface deformation of an area of $88 \mathrm{~km}^{2}$ centered on the Xiwang Road ground fissure in Shunyi District, Beijing, to clarify the relationship between the surface deformation and the factors affecting the ground fissure activity. To reduce the errors due to overlap and contraction caused by radar-side looking imaging, we used a combination of ascending and descending orbit data to carry out the inversion of surface deformation in the study area. Thirty-seven images of Sentinel-1 ascending data from May 2017 to May 2020 and 12 images of descending data from December 2018 to December 2019 were selected. We also selected two Landsat 8 OLI images to detect the land cover changes in the study area based on support vector machine (SVM)-supervised classification, so as to examine the effects of human engineering activities on the ground fissure displacement activity. Finally, combining the results of SBAS-InSAR and land cover change detection, we explored in detail the factors affecting the activity of the Xiwang Road ground fissure to provide a scientific basis and technical reference for the prevention and treatment of ground fissures.

\section{Introduction}

Ground fissures are a common ground deformation phenomenon in daily life. Their locations are often concealed, and the disasters caused by ground fissures often appear to randomly occur. They have caused direct damage to many types of engineering construction projects, such as linear engineering projects, water conservation facilities, and urban buildings. ${ }^{(1-3)}$ Ground fissures also restrict the development of urban planning, land use, groundwater, and urban underground space; seriously threaten the safety of life and property; and inhibit the development of the social economy. Therefore, research on the deformation mechanism of ground fissures and the factors affecting their activity is urgently required, so as to provide a strong judgment basis for the early warning and assessment of the potential risk of ground fissures $^{(4)}$ to prevent and respond to disasters in a coherent manner.

*Corresponding author: e-mail: sushan787426@163.com https://doi.org/10.18494/SAM.2020.3151 
The displacement activity of ground fissures is an important reference index to evaluate the activity of ground fissures. The accurate, comprehensive, and real-time acquisition of deformation variables of ground fissures has already become the main goal of research in this direction. In Ref. 5, a shape acceleration array (SAA) sensor was used to monitor the internal soil mass of the Xiwang Road ground fissure located in Shunyi District, Beijing. The measurement results were comprehensively analyzed by two methods based on instantaneous total energy and displacement. Finally, by combining the results with historical research data, the activity mechanism of this ground fissure was obtained and the factors affecting its activity were briefly summarized. ${ }^{(5)}$ Although an SAA can precisely monitor the displacement of soil within ground fissures, it is difficult to express the effects of regional environmental factors on the deformation mechanism and activity rate of ground fissures. In recent decades, radar remote sensing has become an important remote sensing technology for earth observation because of its advantages of all-day, all-weather use, high spatial resolution, and insensitivity to the effects of the atmosphere and season. Synthetic aperture radar (SAR) images contain abundant amplitude, phase, and other information. As a processing technology of radar satellite remote sensing, interferometric synthetic aperture radar (InSAR) mainly uses the phase data of two or more SAR images covering the same area at different times to carry out interferometric processing and can obtain the surface deformation with millimeter-level accuracy. ${ }^{(6,7)}$ Finally, the time-series deformation results of the monitored area are provided in the form of annual average deformation. InSAR technology has been widely used in 3D terrain reconstruction and in glacier drift, landslide, earthquake, and other deformation monitoring projects. ${ }^{(8-11)}$

Small baseline subsets interferometric synthetic aperture radar (SBAS-InSAR) ${ }^{(12,13)}$ is a new time-series InSAR analysis method proposed by Berardino et al., in which the temporal deformation of coherent targets (CTs) is obtained by their phase analysis. By optimizing the time interval and Doppler frequency of image pairs, more coherent differential interference pairs are formed. Finally, phase change models are obtained and converted into CT time-series deformation. Compared with the traditional differential InSAR (D-InSAR) method, SBASInSAR overcomes the limitations of temporal and spatial correlations and atmospheric effects. ${ }^{(14-17)}$ Compared with the persistent scatterer InSAR (PS-InSAR) method, it uses images with a short space baseline to improve the coherence of interferograms, and the obtained deformation sequence is more continuous in space-time, so it can be applied to monitor the long-term slow deformation of the earth's surface.

Geological disasters are irreversible, and once the development of a ground fissure is out of control, regional economic losses will be very large. Therefore, it is essential to carry out the long-term effective monitoring of ground fissures and investigate the factors affecting them. This paper is based on the research of the activity mechanism of the Xiwang Road ground fissure in Ref. 5. Using the results of SBAS-InSAR and land cover change detection, we discuss in depth the factors affecting the displacement activity of the Xiwang Road ground fissure from quantitative and qualitative perspectives. 


\section{Study Area}

As the capital of China, Beijing is a rapidly developing city with a large population, and its water demand is huge. About two-thirds of the urban water supply comes from groundwater, ${ }^{(18)}$ which has led to the long-term overexploitation of groundwater resources. This has aggravated the occurrence and development of geological disasters such as fault structures and ground fissures in Beijing. The Xiwang Road ground fissure in Shunyi District of Beijing is located to the west of the Jing-Cheng Expressway, with the Sixth Ring Expressway to the north and Fangshi Canal approximately to the south. In the west and north of the ground fissure, the maximum vertical displacement is $18 \mathrm{~mm} /$ year. $^{(19)}$ In this paper, the Xiwang Road ground fissure located in the Gaoliying fault zone is taken as the research focus, and the study area, which has an area of $88 \mathrm{~km}^{2}$, consists of the ground fissure and its surrounding area. The distances between the the Xiwang Road ground fissure and the south, west, north, and east boundaries of the study area are about 16.2, 13.6, 13.6, and $17.1 \mathrm{~km}$, respectively. The study area is mainly composed of woodland, farmland, villages, highways, Beijing Capital International Airport, and other production and living sites. The study area is shown in Fig. 1.

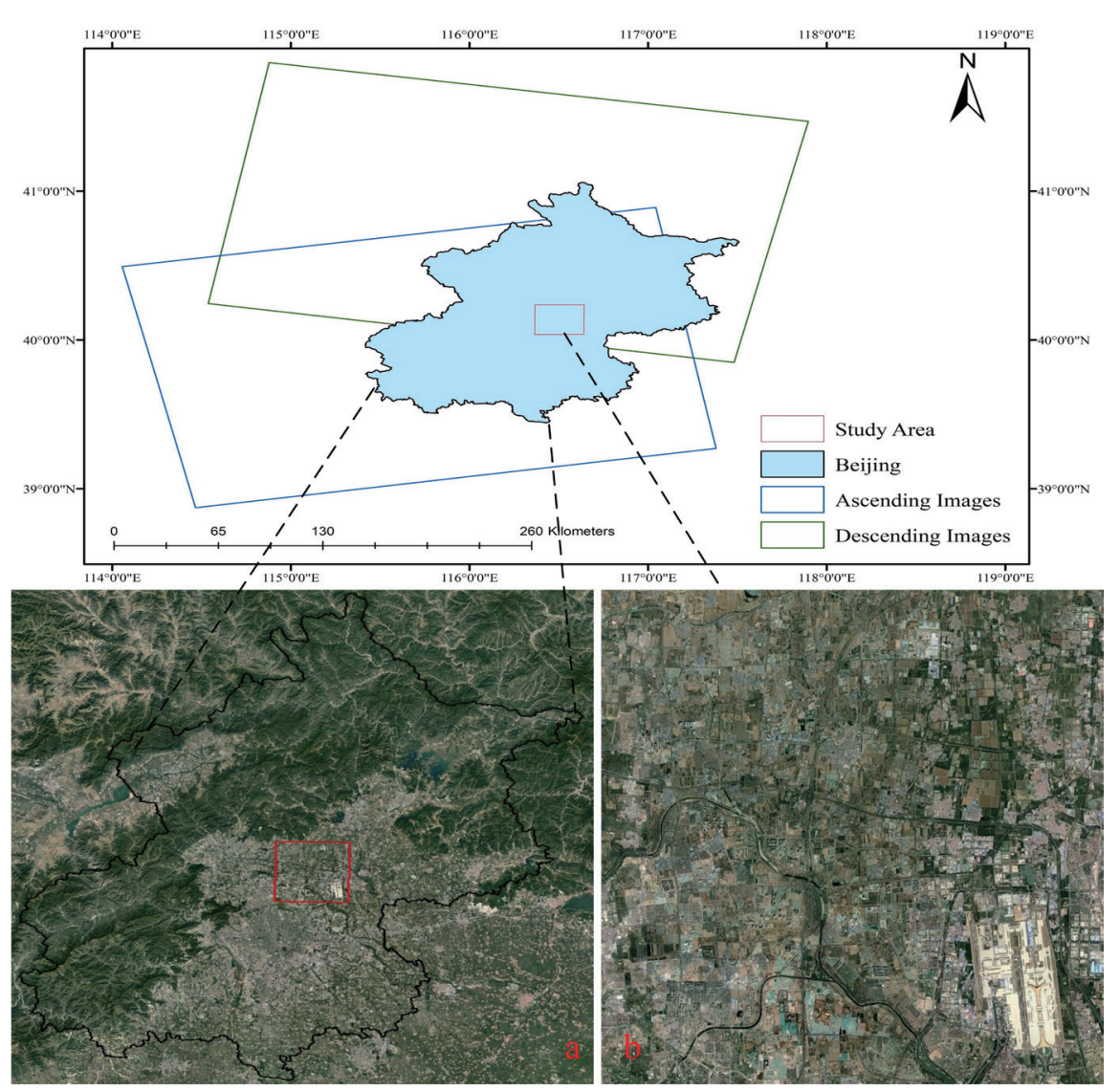

Fig. 1. (Color online) Geographical environment of study area. (a) Relative locations of study area and Beijing and (b) study area. 


\section{Methodology}

\subsection{Data source}

The research content of this paper is based on ESA Sentinel-1 $(5 \times 20 \mathrm{~m}$ ground resolution) SAR data. The Sentinel-1 imaging system based on the C-band adopts four imaging modes, i.e., the interferometric wide swath (IW), wave mode (WM), strip map (SM), and extra wide swath (EW), with single or dual polarization. It has a short revisit period and rapid product production, and can accurately determine the satellite position and attitude angle. In this work, the IW imaging mode, which performs terrain observation with progressive scans SAR (TOPSAR), is used. Owing to the side-view imaging mechanism of SAR, there are some problems in the geometric imaging of areas with complex terrain, such as range compression, shadow, and overlay, which lead to the observation of slope deformation in some areas or directions. Therefore, the descending data are used as supplementary data to the ascending data to reduce such problems. In the selection of data, historical weather conditions are combined to avoid SAR images taken under poor weather conditions such as rainfall and snowfall. Finally, we obtain 37 ascending orbit images from May 2017 to May 2020 and 12 descending orbit images from December 2018 to December 2019. The polarization mode is VV polarization. In the 37 ascending images, the maximum time interval is 48 days and the minimum time interval is 12 days. In the 12 descending images, the maximum time interval is 84 days and the minimum time interval is 12 days. As the necessary digital elevation model (DEM) data to remove the terrain phase, the Advanced Spaceborne Thermal Emission and Reflection Radiometer Global Digital Elevation Model (ASTER GDEM) with a resolution of $30 \mathrm{~m}$ is selected.

For the detection of land cover changes in the study area, we select two Landsat 8 operational land imager (OLI) images covering the study area in December 2017 and November 2018. Landsat 8, the eighth satellite of the Landsat program of the United States, was launched on February 11, 2013, and carries an OLI and a thermal infrared sensor (TIRS). The OLI images consist of nine bands with a spatial resolution of $30 \mathrm{~m}$, including a $15 \mathrm{~m}$ panchromatic band with an imaging width of $185 \times 185 \mathrm{~km}$.

\subsection{SBAS-InSAR technology}

SBAS-InSAR uses image pairs with short time and space baselines to generate interferograms to improve coherence. The multilook processing of the differential interferogram can reduce the phase noise and extract the target with high coherence. After the average deformation velocity is estimated by differential interference calculation, the effect of the atmosphere can be removed by a high-pass filter in the time domain and a low-pass filter in the space domain.

Firstly, SAR image and DEM data preprocessing is carried out for the study area, which mainly includes image registration and clipping. Time-series interferograms are generated by combining SAR image data after preprocessing, and the differential interferogram is calculated. We suppose that there are $n$ single-look complex (SLC) SAR images preprocessed using the time series. First, they are registered with any image as the main image. Then, the thresholds 
of the spatial and temporal baselines are set. The threshold of the time baseline is set to 365 days, and the maximum threshold of the spatial baseline is set to $45 \%$. The image pairs meeting the threshold conditions are classified into a group of differential interferograms, and the interference phase is calculated for each group of images to generate interferograms. Owing to the effects of the reference ellipsoid and terrain phase, the phase of flat ground and terrain should be removed from an interferogram composed of CT points. In addition, the phase values at the $[-\pi,-\pi]$ interval are recorded in the differential interferometric phase diagram. However, there will be a difference of $2 k \pi$ between the real phase and the differential interferometric phase. Therefore, phase unwrapping is used to recover the integer number of the blurred phase $2 k \pi$, then the differential interference results of all image pairs are obtained. Then, the phase of the differential interferogram is estimated in the time and space domains to remove the residual phase containing the atmosphere and noise. Using the radar wavelength parameters, the unwrapping phase is converted into the line-of-sight (LOS) time-series deformation phase of point targets. Finally, the LOS deformation velocity is converted into the vertical deformation velocity using the radar incident angle. The deformation and velocity mentioned in this paper are in the vertical direction. Figure 2 shows the technical flow chart of SBAS-InSAR.

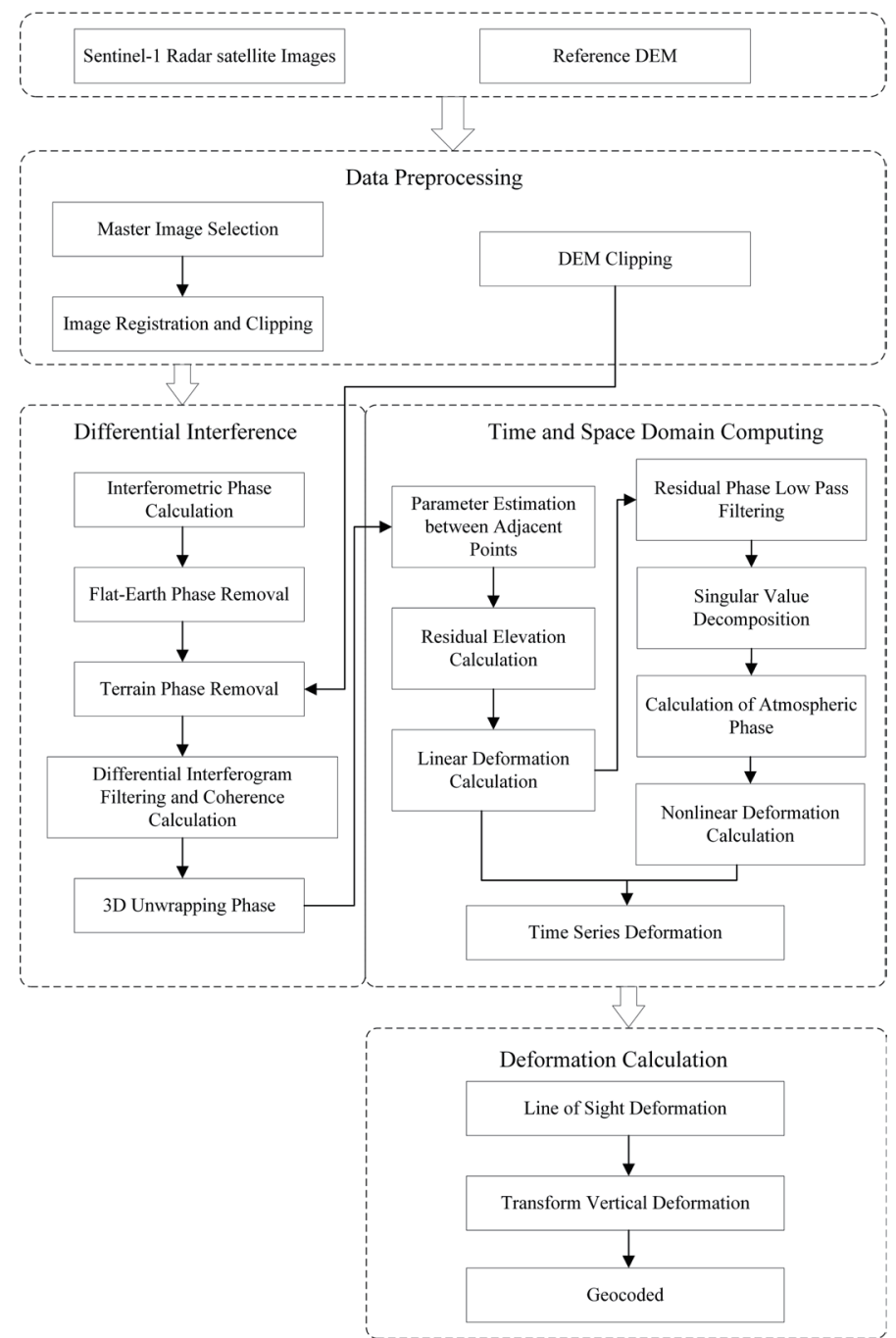

Fig. 2. Technical flow chart of SBAS-InSAR. 


\subsection{Change detection based on SVM-supervised classification}

SBAS-InSAR can provide the ground deformation reference data for inferring the factors affecting the activity of the Xiwang Road ground fissure. However, it is not enough to further investigate the environmental factors only by considering the surface deformation. Therefore, we also detect changes in land cover in the study area using Landsat 8 data to examine the effects of human activities on the surface subsidence and ground fissure.

Firstly, the Landsat 8 data in December 2017 and November 2018 are obtained, and the image data are preprocessed by clipping, registration, radiometric correction, and atmospheric correction. As the study area is urban Beijing, synthetic pseudo-color images of seven, six, and four bands are used. Synthetic pseudo-color images are shown in Fig. 3.

In addition, before the detection of land cover changes, we first classify the surface features using a support vector machine (SVM), ${ }^{(20)}$ which is essentially a supervised learning classification method. This method determines the decision boundary of a classification problem from the maximum-distance hyperplane of learning samples. Figure 4 is a simple

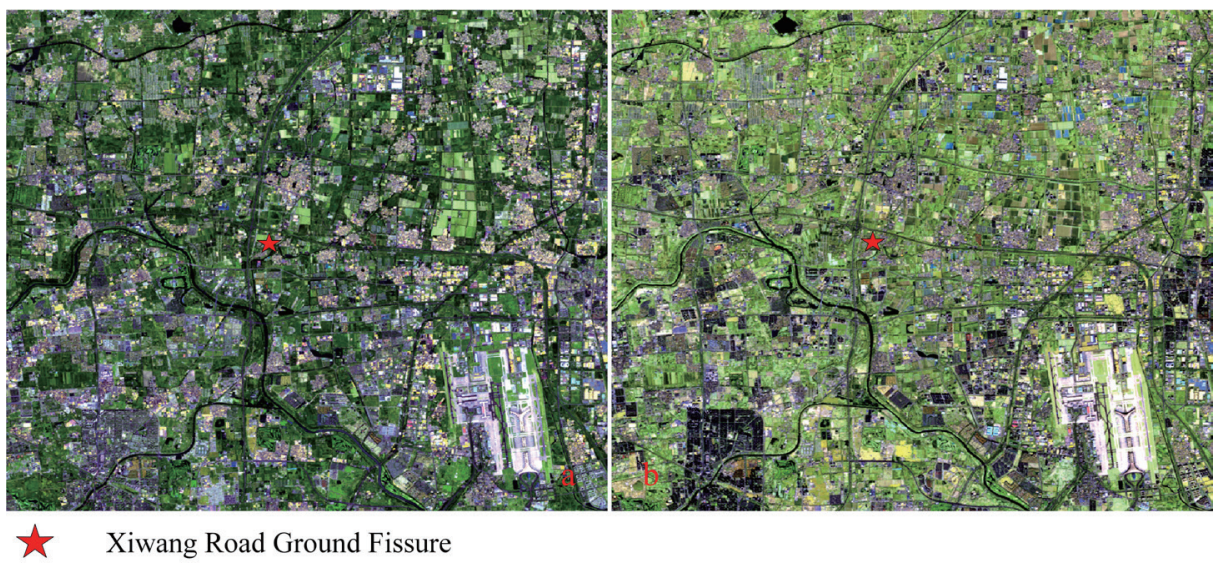

Fig. 3. (Color online) Pseudo-color synthetic images of seven, six, and four bands. (a) Atmosphere-corrected image of November 2017 and (b) atmosphere-corrected image of December 2018.

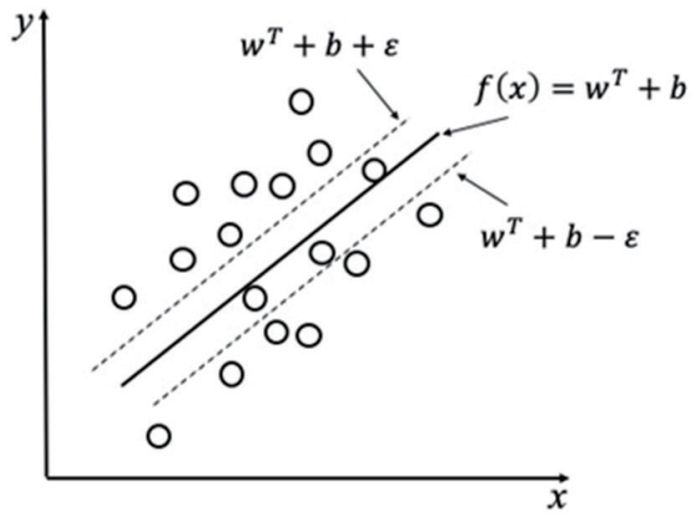

Fig. 4. Simple schematic diagram of SVM method. 
schematic diagram of the SVM method, where $f(x)=w^{T} x+b$ is the regression line, the vector $w^{T}$ is the weight of the SVM model, and the vector $b$ is the offset. The SVM method involves adjusting the training parameters $w$ and $b$ to make $f(x)$ most closely approach $y$, which is the maximum allowable deviation between $f(x)$ and $y$. The SVM method is more suitable for training small samples of data, and the training effect of the model is ideal for our purpose. The development of the algorithm used in the SVM method has reached the mature stage, and the method has good robustness.

\section{Results and Discussion}

\subsection{Deformation results of Xiwang Road ground fissure based on SBAS-InSAR}

Figure 5 shows the deformation rate diagram of the Xiwang Road ground fissure settlement direction, where the red frame indicates the region of interest (ROI). It can be seen from the figure that local incoherence leads to no measured deformation points, but the overall deformation trend is obvious. The average annual deformation rate of the Xiwang Road ground fissure is positive, indicating uplift, while the average annual deformation rate of its west and east is negative, showing a subsidence trend.

As there are many deformation points measured in the ROI, the points whose absolute annual average deformation velocity is greater than $5 \mathrm{~mm} /$ year are extracted separately. There are 26 points meeting the condition, and their positions are shown in Fig. 6 . It can be clearly seen that there was no significant displacement of the Xiwang Road ground fissure from May 2017 to May 2020. Figure 7 shows the monthly displacement of these 26 points. The overall activity trend is similar for each point, but there is a large difference from April to July 2018 (center red frame in Fig. 7), with some points uplifting and other points settling. Because of the strong periodicity of the deformation trend, the active period of the ground fissure is preliminarily determined to be caused by seasonal rainfall and other meteorological factors.

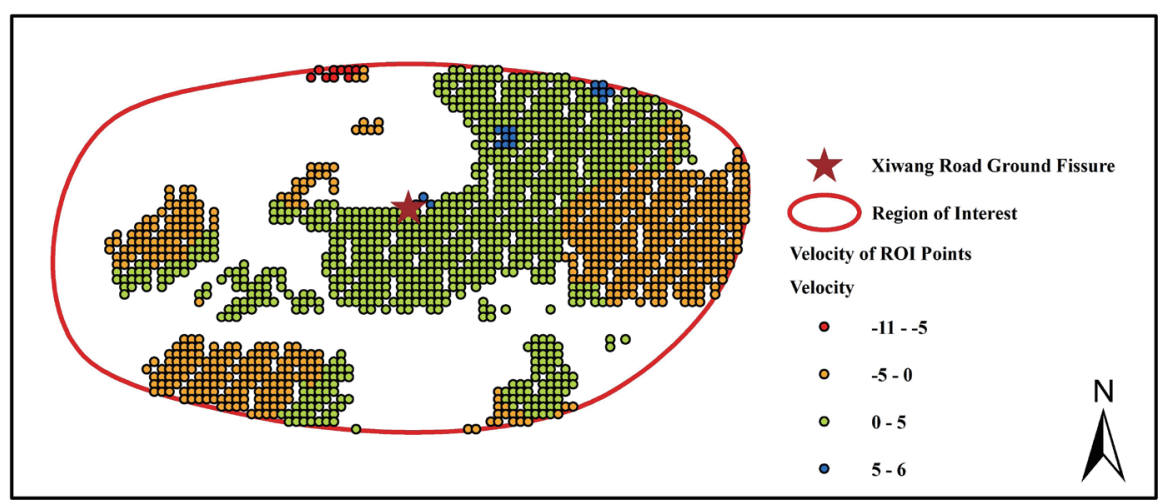

Fig. 5. (Color online) Deformation rate diagram of Xiwang Road ground fissure. 


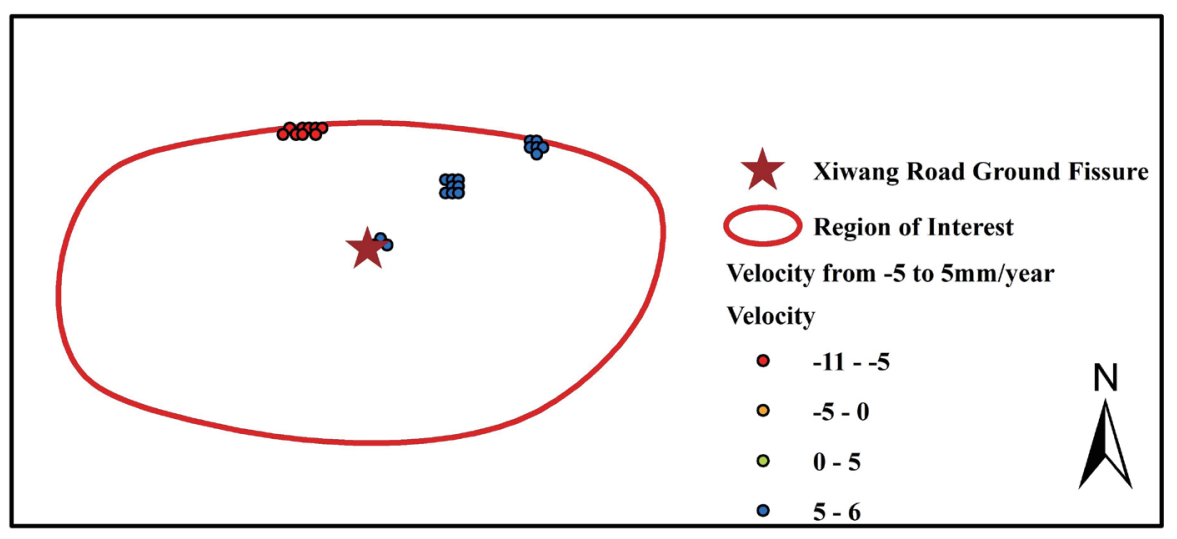

Fig. 6. (Color online) Points whose absolute annual average deformation velocity is greater than $5 \mathrm{~mm} /$ year.

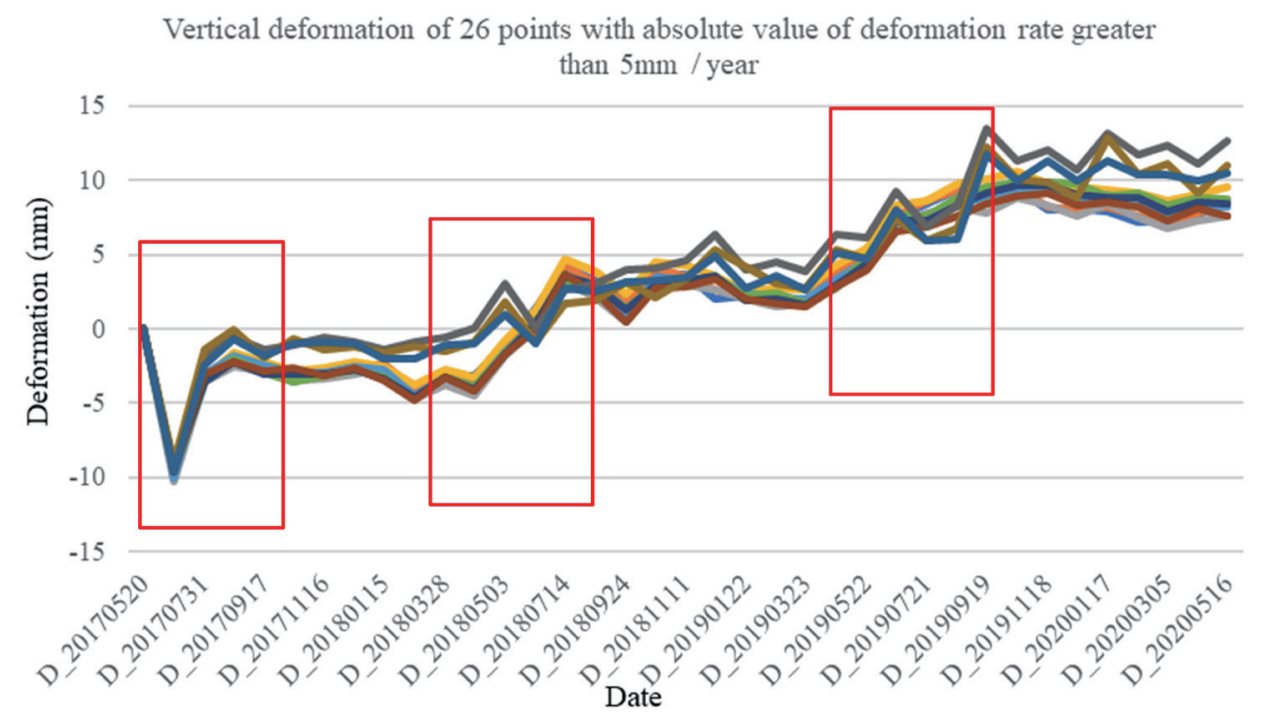

Fig. 7. (Color online) Monthly displacement of points whose absolute annual average deformation velocity is greater than $5 \mathrm{~mm} /$ year.

\subsection{Results of land subsidence in study area obtained by SBAS-InSAR}

Figure 8 shows the results of surface subsidence in the study area obtained by SBASInSAR. In the study area, the maximum vertical deformation rate is about $-48 \mathrm{~mm} / \mathrm{year}$, and the deformation rate of the whole study area is mainly from -10 to $10 \mathrm{~mm} / \mathrm{year}$. However, it can still be clearly seen from the figure that the northwest and southeast of the Gaoliying fault zone are subsidence and uplift areas, respectively, which indicates that the Gaoliying fault zone plays a central role in the development of the Xiwang Road ground fissure. There are three pumping wells in the northeast of the fault zone. With the large amount of groundwater exploitation, the groundwater level has been dropping year by year, which has caused the water level of the confined aquifer to fluctuate greatly. Therefore, serious land subsidence has resulted, accelerating the degree of cracking of the Xiwang Road ground fissure. In addition, the SBAS- 


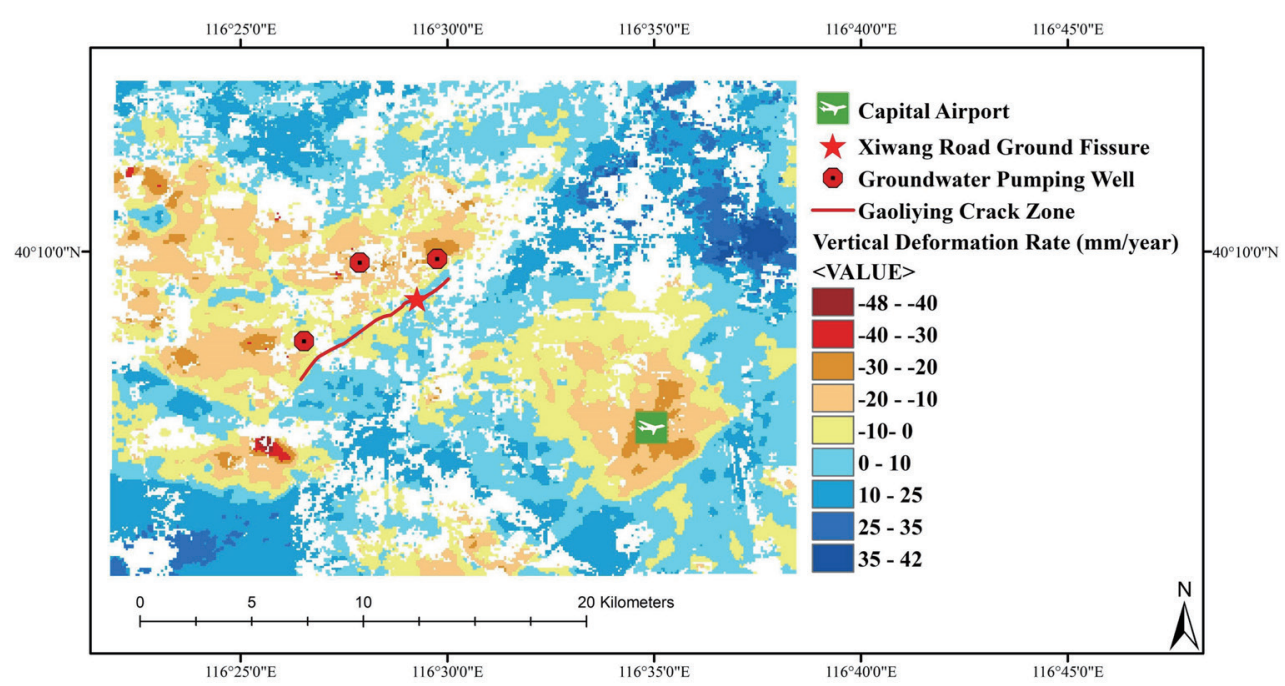

Fig. 8. (Color online) Results of surface subsidence in study area obtained by SBAS-InSAR.

InSAR monitoring results show that there is a relatively distinctive settlement center in the southeast of the Gaoliying fault zone that has radiated to the surrounding area, forming a larger settlement area. By consulting the geographical data, it is confirmed that this area corresponds to the airport. Depending on the location and size of the settlement area, we think that the settlement area will have a slight impact on the displacement activity of the settlement direction of the Xiwang Road ground fissure. However, the offset of the ground fissure is mainly due to the control of the Gaoliying fault zone and the uneven subsidence caused by groundwater recession. For the two clear uplifting areas in the southwest and northeast of the Xiwang Road ground fissure, further analysis is next carried out in combination with the detection results of land cover changes.

\subsection{Detection of land cover changes based on Landsat 8 images}

Before the detection of land cover changes from Landsat 8 images, the SVM is used to supervise the classification of pseudo-color synthetic images of Landsat 8 data in December 2017 and November 2018. Because our main interest here is the impact of human activities on the ground fissure, only two categories are used in the classification, namely, building land and non-building land and roads. One hundred and fifty samples are used for building land and 160 samples are used for non-building land and roads. The final supervised classification results are shown in Figs. 9(a) and 9(b).

After classifying the images by SVM, the method of setting the image difference threshold is used to detect the newly added and removed surface buildings in the study area. The detected changes are shown in Fig. 9(c). It can be seen that from November 2017 to December 2018, the surface coverage of buildings mainly increased, with sporadic areas converted from building land to non-building land mostly distributed around areas with new buildings. According to the high-definition map combined with our knowledge of the area, the area with reduced surface 


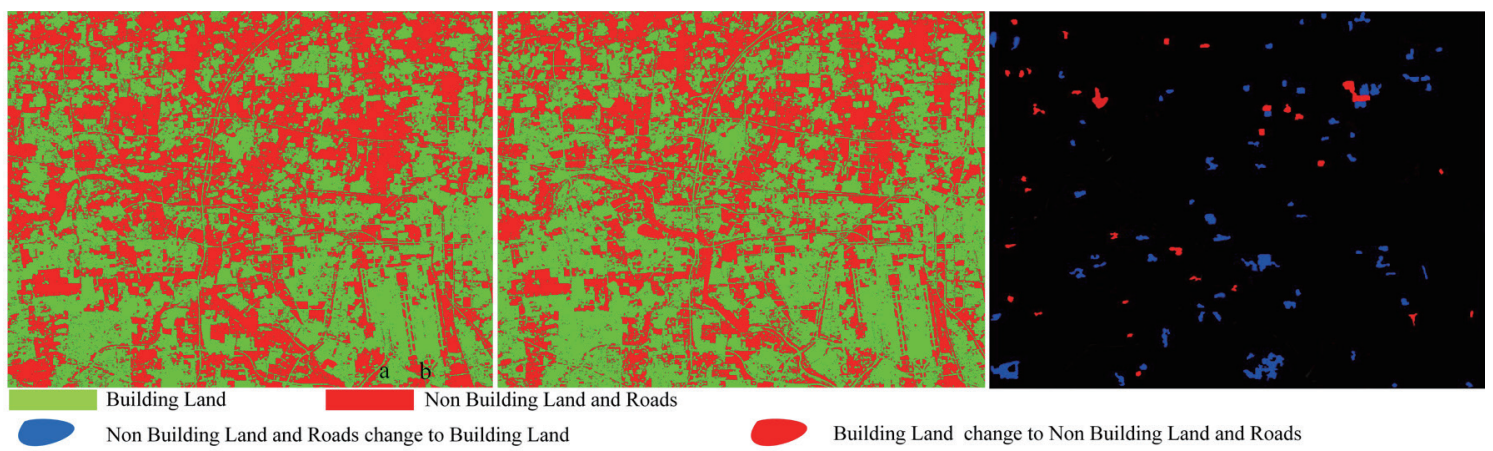

(a)

(b)

(c)

Fig. 9. (Color online) Supervised classification results. (a) Image classification result in November 2017, (b) image classification result in December 2018, and (c) result of change detection.

cover was basically caused by the demolition of construction project facilities. However, the construction and demolition of such short-term construction sites will not have a significant impact on ground fissures. Therefore, after excluding the part with reduced land cover shown in red, the remaining blue part, that is, the area with new buildings, is more consistent with the land subsidence area. From the results of SBAS-InSAR land subsidence and surface cover change detection, it is found that human construction activities induce land subsidence, which increases the risk of ground fissure deformation. Therefore, human construction activities will aggravate the development of ground fissures, thus increasing the possibility of property losses caused by ground fissures.

\section{Conclusions}

In this study, we integrated time series InSAR and optical remote sensing land change detection technology using the method of "quantitative" measurement combined with "qualitative" judgment of land subsidence and human engineering disturbance information, and finally comprehensively determined the factors affecting the Xiwang Road ground fissure activity. The specific conclusions are as follows:

(1) SBAS-InSAR is a very effective monitoring method for geological disasters resulting from slow changes and can reflect the spatiotemporal variations in the characteristics of ground fissures through a long time series obtained by surface deformation monitoring. Combined with the incentive effect of the study area environment, it is determined that the Xiwang Road ground fissure is in the development state. Although the annual change is relatively stable, the activity in April to July of each year was more intense in the three-year monitoring cycle, which indicates that the Xiwang Road ground fissure is more actively changing in this period.

(2) InSAR surface deformation monitoring results are often disturbed by human activities, such as the construction and demolition of buildings, which reduce the ability to make effective judgments of geological disasters. Geological hazard monitoring based on cooperative optical and radar remote sensing is therefore a superior method. In particular, the detection 
of short-term changes in surface cover can eliminate incorrect deformation information and form a better identification system.

(3) The fault structure of the Gaoliying fault zone is the main factor contributing to the formation of the Xiwang Road ground fissure. Also, the overexploitation of groundwater has aggravated the development of the ground fissure. In addition, frequent human engineering activities and the occurrence of bad weather have contributed to its development.

We have adopted a method of time-series deformation and the detection and analysis of changes in surface cover to increase the effectiveness and comprehensiveness of the analysis of factors affecting the activity of the Xiwang Road ground fissure, providing reference values for the prevention of a ground fissure disaster and the response to such a disaster. However, there are still some shortcomings of our approach. For example, the time scale of our detection of land cover changes is short, which should be extended in future research.

\section{References}

1 C. F. Lee, J. M. Zhang, and Y. X. Zhang: Eng. Geol. 43 (1996) 45. https://doi.org/10.1016/0013-7952(95)000887

2 J. B. Peng, X. H. Sun, W. Wang, and G. C. Sun: Environ. Earth Sci. 75 (2016) 1190. https://doi.org/ 10.1007/ s12665-016-5928-3

3 Y. Ge, H. Tang, X. Gong, B. Zhao, Y. Lu, Y. Chen, and Y. Qiu: Sensors 19 (2019) 1463. https://doi.org/10.3390/ s19061463

4 R. Macciotta, M. Hendry, and C. D. Martin: Nat. Hazards 81 (2015) 887. https://doi.org/10.1007/s11069-015$2110-2$

5 X. Liu, S. Su, J. Ma, and W. Yang: Sensors 19 (2019) 2607. https://doi.org/10.3390/s19112607

6 L. Zhu, H. L.Gong, L. L. Jing, Y. M. Su, X. J. Li, and J. Jiang: 2009 Joint Urban Remote Sensing Event (IEEE, 2012) 1-5. https://doi.org/10.1109/urs.2009.5137693

7 D. L. Galloway and T. J. Burbey: Hydrol. J. 19 (2011) 1459. https://doi.org/10.1007/s10040-011-0775-5

8 A. Gualandi, E. Serpelloni, and M. E. Belardinelli: Geophys. J. Int. 197 (2014) 174. https://doi.org/10.1093/gji/ ggt522

9 T. Strozzi, A. Luckman, T. Murray, U. Wegmuller, and C. L. Werner: Remote Sens. 40 (2002) 2384. https:// doi.org/10.1109/tgrs.2002.805079

10 B. Bayer, A. Simoni, D. Schmidt, and L. Bertello: Eng. Geol. 226 (2017) 20. https://doi.org/10.1016/ j.enggeo.2017.03.026

11 M. Amighpey and S. Arabi: Remote Sens. Appl.: Soc. Environ. 4 (2016) 1. https://doi.org/10.1016/ j.rsase.2016.04.001

12 P. Berardino, G. Fornaro, R. Lanari, and E. Sansosti: IEEE Trans. Geosci. Remote Sens. 40 (2002) 2375. https://doi.org/10.1109/tgrs.2002.803792

13 R. Lanari, O. Mora, and M. Manunta: IEEE Trans. Geosci. Remote Sens. 42 (2004) 1377. https://doi. org/10.1109/tgrs.2004.828196

14 C. Werner, U. Wegmuller, T. Strozzi, and A. Wiesmann: Proc. 2003 IEEE Int. Geoscience and Remote Sensing Symp. (IEEE, 2003). https://doi.org/10.1109/igarss.2003

15 R. Lanari, F. Casu, M. Manzo, G. Zeni, P. Berardino, M. Manunta, and A. Pepe: Pure Appl. Geophys. 164 (2007) 637. https://doi.org/10.1007/s00024-007-0192-9

16 C. Zhou, H. Gong, B. Chen, F. Zhu, G. Duan, M. Gao, and W. Lu: Gisci. Remote Sens. 53 (2016) 671. https:// doi.org/10.1080/15481603.2016.1227297

17 Z. Chen, W. Jiang, W. Wang, Y. Deng, B. He, and K. Jia: Remote Sens. 10 (2017) 4. https://doi.org/10.3390/ rs10010004

18 C. Zhou, H. Gong, B. Chen, J. Li, M. Gao, F. Zhu, and Y. Liang: Remote Sens. 9 (2017) 380. https://doi. org/10.3390/rs9040380

19 G. Cheng, H. Wang, Y. Luo, and H. Guo: Proc. Int. Assoc. Hydrological Sciences 372 (2015) 231. https://doi. org/10.5194/piahs-372-231-2015

20 P. Mantero, G. Moser, and S. B. Serpico: IEEE Trans. Geosci. Remote Sens. 43 (2005) 559. https://doi. org/10.1109/tgrs.2004.842022 


\section{About the Authors}

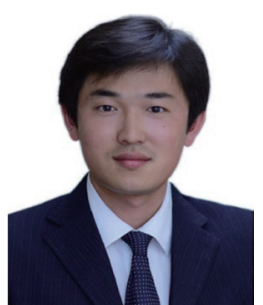

Xi Liu received his B.S. degree from Heilongjiang Institute of Technology, China, in 2004 and his M.S. degree from Wuhan University, China, in 2012. $\mathrm{He}$ is a senior engineer of Heilongjiang Surveying and Mapping Instrument Calibration Station. His research interests are in UAV remote sensing, multisource remote sensing fusion, and sensor verification.

(liuxi0101@163.com)

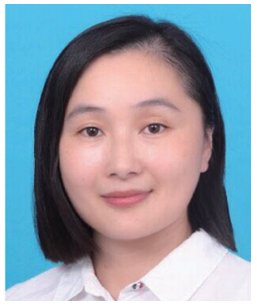

Jing Ma received her M.S. degree from Chang'an University, China, in 2008. She is a vice-senior engineer of Beijing Institute of Geological and Prospecting Engineering. Her research interests are in geological hazard monitoring, InSAR, and SAA sensors. (majing2001@163.com)

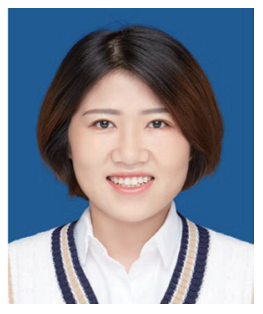

Shan Su received her B.S. degree from Heilongjiang Institute of Technology, China, in 2017 and her M.S. degree from Beijing University of Civil Engineering and Architecture, China, in 2020. Her research interests are in remote sensing image classification and geological hazard monitoring. (sushan787426@163.com) 